\title{
A Habermasian Approach to the Examination of Language Teachers' Cognitive Interests
}

\begin{abstract}
Language teacher educators train pre-service teachers in numerous theories and pedagogical practices of language learning and language teaching. They expect that their student teachers will translate this conceptual and practical knowledge into action during their practicum. However, in the process of determining pre-service teachers' readiness for the field experience and the profession in general, methods classes measure only their conceptual knowledge and omit looking at their student teachers' belief system about language teaching and learning. This belief system is a strong indicator of how the students organize their knowledge for application (Borg, 2003) and may help teacher educators gauge students' read ness in the use of new pedagogies that these pre-service teachers may not have experienced before. Using two reflective essays and a piece of authentic assessment as instruments to gather data, as well as Jürgen Habermas's theory on cognitive interests as a framework to explore the espoused beliefs of nine pre-service language teachers at the end of a methods course, this qualitative study addressed the following questions: What levels of cognitive interests do the nine pre-service world language and ESL teachers exhibit prior to student teaching? To what extent do the students' levels of cognitive interests change during the methods course called Teaching a Second Language? What are the most common cognitive interests regarding such areas of teaching performance, such as methodology and assessment among the participants? The results show that the nine pre-service teachers held mostly technical and some practical cognitive interests at the beginning of the semester. In the end, most of the participants held practical interests, and three out of the nine pre-service teachers held elementary emancipatory beliefs. One pedagogical recommendation is to include experiences in the training of pre-service teachers that promote emancipatory beliefs that could support teachers in their pursuit of transforming challenging social conditions while examining and adopting new pedagogies.
\end{abstract}

Keywords: pre-service language teachers, cognitive interests, technical interests, practical interests, emancipatory interests, Habermas 


\section{Introduction}

Methods courses play a pivotal role in the development of a teacher. They provide the foundational work that would assist the students in applying the theory to real academic contexts. Most of these methods courses use case studies, lesson plans, micro-teaching sessions, and formal paper-and-pencil exams to gain a perspective about their pre-service teachers' level of preparedness for their field experience and the profession in general. Even though these evaluations could help determine their level of understanding of concepts, teacher educators soon find that once in the field, pre-service teachers have a hard time using this theoretical knowledge to act on either a typical or challenging practice situation. Therefore, it is imperative that teacher educators examine not only pre-service language teachers' conceptual and practical knowledge but also their beliefs in order to help determine their level of preparedness prior to student teaching. As Varghese et al. (2005) said,

In order to understand language teaching and learning we need to understand teachers; and in order to understand teachers, we need to have a clearer sense of who they are; the professional, cultural, political, and individual identities, which they claim or which are assigned to them. (p. 22)

The main goal of this study was to determine the cognitive interests, conceptual knowledge, and espoused beliefs about language teaching and learning of nine pre-service teachers in order to gain knowledge about their different levels of pedagogical preparation and beliefs prior to their student teaching experience. This study applied the theoretical framework of Habermas's cognitive interests to three sources of data (two reflective papers and a piece of authentic assessment) to answer the following questions:

1. What levels of cognitive interests do the nine world-language and ESL preservice teachers exhibit prior to student teaching?

2. Which cognitive interests regarding such areas of teaching performance, such as methodology and assessment, are most common among the participants?

3. To what extent do the students' levels of cognitive interests change, if at all, during the methods course called Teaching a Second Language? 


\section{Literature Review}

\section{Language Teacher Cognitions}

The meaning of the term teacher cognition in this paper relates to the teacher's knowledge of theory and pedagogy and their personal theories and beliefs about teaching (Borg, 2003). In the last two decades, various authors have published several reviews and studies about experienced and novice language teachers' cognition (Basturkmen, 2012; Borg, 2003; Burns, Edwards, \& Freeman, 2015; Gabryś-Barker, 2012; Golombek \& Johnson, 2017; Mann, 2005; Wright, 2010). One of the three themes addressed in Borg's review of the studies done from 1989 to 2000 was cognition and teacher education. He found out that, according to the mainstream research, student teachers develop in diverse ways. Therefore, in order to comprehend the scope of the impact of teacher training programs on student teachers, one should focus on individual cases. Another key theme in his review was that a change in behavior as a result of teacher education does not imply a change in cognition and vice versa. Borg also discovered that future language teachers at the beginning of their studies show distorted or immature understandings of teaching and learning (Brookhart \& Freeman, 1992; Brown \& McGannon, 1998; Cumming, 1989). According to Borg's review, Brookhart and Freeman (1992) found two recurrent future teachers' misunderstandings in their study: that languages were learned by imitation and that errors were caused by L1 interference. A recent study on pre-service teachers' beliefs (Debreli, 2016) reported that the majority of the 16 pre-service teachers from Cyprus trusted the methods presented as effective in a teacher education program. These methods were also the main influential factors in shaping their beliefs.

Basturkumen's (2012) review showed that most of the studies reported a "limited correspondence" between experienced teachers' espoused beliefs and their classroom practices. Those studies also supported the influence of the context and teachers' years of experience in terms of facilitating or restricting the execution of teachers' beliefs. These groups of studies determined that the beliefs of experienced teachers were more evident in their pedagogical choices and behaviors than those beliefs from novice teachers. Only two dissertation studies from Basturkurmen's review reported results related to pre-service teacher beliefs. Sinprajakpol's (2004) research found limited correspondence between pre-service teachers' beliefs about language teaching and learning approaches and their classroom practices; Vibulpol's (2004), on the other hand, found correspondence between the teachers' beliefs about their own language skills and the importance of grammar in their choice of approaches in the classroom. Despite the disagreement between Sinprajakpol's (2004) and Vibulpol's (2004) results, it is clear that pre-service language teachers' beliefs are mostly 
influenced by their experiences as students and by emergent understandings of what are considered good practices in the field.

Gabryś-Barker's (2012) qualitative study about the beliefs of a group of pre-service teachers about language teaching shows that teachers' earlier experiences as language students play a pivotal role in the shaping of their beliefs about teaching. These trainees, as the study describes them, perceive teachers as experts, sharers of knowledge, and ones with a clear mission. The participants' perceptions of their future roles as teachers "implies the need for a teacher's active involvement: both professional and personal, creativity and responsibility and also the courage to be different and the need to go on trying, irrespective of failures and obstacles" (48). Burns, Edwards, and Freeman (2015) summarized the main ontological approaches used from 1990 to 2014 by a group of studies (Crookes, 2010; Freeman \& Johnson, 1996; Kubanyiova, 2012) and their goal to understand the mind of the language teacher. The bulk of this research highlights the importance of understanding the pre-service teachers' values, beliefs, and histories as learners if teacher programs want to be effective in their goal to not only shape but also to transform teachers' practices. Hennisen, Beckers, and Moerkerke (2017) studied the effectiveness of a curriculum in helping 136 pre-service teachers link theory with practice. The results showed growth in their knowledge and new schema formations after the pre-service teachers participated in a curriculum designed using an inductive approach that includes in-the-field experiences, post-experience reflections, and pre-service teachers' concerns. Most of the studies above have used teachers' narrative inquiry in their study design as a "systematic exploration that is conducted by teachers and for teachers through their own stories and language" (Johnson \& Golombek, 2002, p. 6). This study will contribute to this body of research by expanding the field's understanding of pre-service cognitive interests by offering a theoretical framework to help shape our understanding of pre-service language teachers. A Habermasian lens helps to capture the complexity and dynamic nature of cognitive beliefs by being able to explore emancipatory ways of thinking about language-learning practices.

\section{Cognitive Interest Framework}

Jürgen Habermas's (1971) theory of cognitive interests offers a framework for looking at diverse knowledge, beliefs, and dispositions in order to gain a wider perspective on pre-service teachers' cognitive interests. This framework not only explores specific orientations in conceptual knowledge, but it also looks at people's interests in connecting with a community and explores issues of power. The two latter foci allow a framing of our understanding of student teachers' belief systems from a socio-critical perspective much needed 
during these times, when language classes are being cut and second language requirements are either being substituted with other content areas, such as coding, or simply eliminated. Therefore, teachers need to develop a critical lens to understand their own precepts and those of the community in order to become strong advocates for the profession. Furthermore, this theory of cognitive interests helps to capture the complexity and dynamic nature of pre-service language teachers' tenets.

Habermas (1971) stated that people function in a combination of domains based on specific orientations in their beliefs. These domains of human activity are classified into three cognitive interest domains:

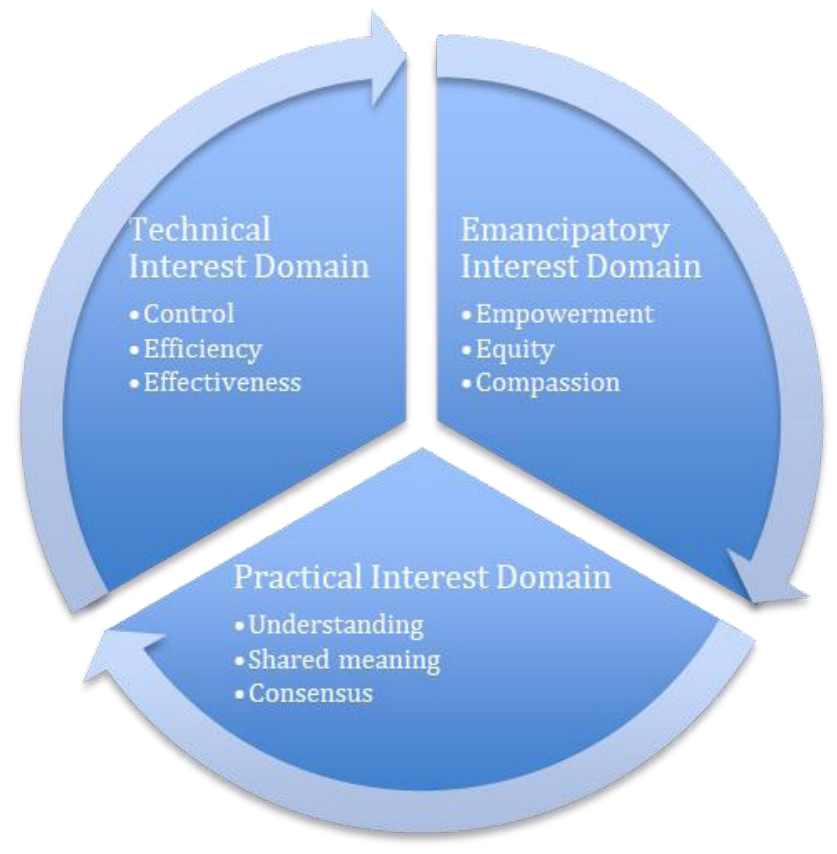

Figure 1. Domains of Human Interests (Habermas, 1971)

Teachers functioning at a technical-interest level focus on the desire to control their professional environment by following pre-established precepts (Scott, 1997) to meet specific academic needs. The focus is "on efficiency and effectiveness" (Geelan, 2001, p. 7). Language educators performing at this level might focus on translations, the memorization of vocabulary lists, and grammar lessons that emphasize repetition and error correction. Teachers aim at controlling discrete chunks of information (Edgar, 2006).

Teachers functioning at a practical-interest level emphasize the importance of understanding the environment and the society around them. They work on developing "interpersonal rapports, understanding, and consensus that facilitate 
positive change for their students" (Kondrat, 1995, p. 409). These teachers look for an understanding of the other and the self (Kondrat, 1995). Language teachers functioning at this level would plan around the students' interests. The goals of communication and cultural understanding would be at the center of their pedagogical decisions (Edgar, 2006).

Finally, teachers operating at an emancipatory level identify issues of power in the classroom and school contexts. They focus on a pedagogy that emphasizes compassion and underscores equity and empowerment for their students and the school community. Language teachers would foster a caring classroom culture where all the participants' voices would have a fair chance to be heard (Edgar, 2006). These teachers would engage in self-reflection (Scott, 1997) and in advocacy efforts for the profession. They would also design lesson plans based on principles of social justice and that would benefit the community (Kondrat, 1995). It is important to highlight that these domains are neither linear nor in hierarchical order. It is advisable that teachers operate in all the domains (Ring, 2014), with one or two domains being more prominent than others.

The profession of social work encourages the inclusion of Habermas's framework to redesign curricula that would address current challenges in the field. For instance, Kondrat (1995) affirmed that incorporating Habermas's domains in the training of social workers would help determine trainees' particular orientations for actions and possible sources of practitioner errors. Ring (2014) argued that a curriculum based on Habermas's domains of cognitive interests would better train social workers in England to deal with an aging population and difficult financial times for social welfare systems. This framework offers an empowerment perspective that is needed in the profession to aid ESL, bilingual, and world-language teachers in their pursuit to transform challenging social conditions "to be more inclusive of diverse and less powerful voices" (Kondrat, 1995, p. 420). Language-teacher education should not only focus on the development of pedagogical skills but also on the development of an educator who could question and transform the implementation of policies that could compromise the future of language learning.

In the process of reviewing the literature, the researcher found studies related to cognitive interests in the field of education. Butler's (1997) thesis looked at the differences in Habermas's cognitive interests between students and their teacher and the impact of these differences on students' performance in three different courses for the adult community. Butler found that students with cognitive interests matching their teacher's performed better than those with different cognitive interests. Scott (1997) examined the beliefs of three college teacher assistants about the teaching and learning of educational technology. His study found that even though the assistants espoused interests in the practical domain, their actions in the actual classroom reflected their interests in the technical domain. This finding correlates with Basturkumen's (2012) review. 
This research will be the first qualitative study in the area of language-learning education that has used Habermas's domains as a framework to understand pre-service language teachers' cognitive interests. This study aims to expand this area of research by offering a theoretical framework that helps frame our understanding of language teachers' cognitive development beyond the descriptive accounts of teachers' beliefs so needed in our field (Kubanyova, 2012).

\section{Methods}

\section{Participants}

A convenience sample of nine pre-service teachers agreed to take part in this study. They were all women between the ages of 20 and 40 who were taking a methods course in language teaching during the data collection stage of this study. Three of these participants were pursuing initial certification in ESL; six were pursuing initial certification in world-language education. Five were undergraduate students, and four were in the post-baccalaureate education program. The following Table 1 provides a complete list of the participants.

\section{Table 1}

Participants

\begin{tabular}{l|l|l|l|l|l|l|l}
\hline Name & Age & Certification & U & P & L1 & L2 & Professional experience \\
\hline Gab & 20 & ESL & X & & English & Italian & N/A \\
\hline Kit & 20 & ESL & X & & $\begin{array}{l}\text { English and } \\
\text { Spanish }\end{array}$ & French & N/A \\
\hline Sam & 20 & Spanish/ESL & X & & English & Spanish & N/A \\
\hline Vic & 20 & Spanish/ESL & X & & English & $\begin{array}{l}\text { Spanish and } \\
\text { German }\end{array}$ & N/A \\
\hline Mer & 36 & Spanish & X & & Spanish & English & Worked in banking \\
\hline Ele & 25 & ESL & & X & English & Greek & $\begin{array}{l}\text { Worked from home- } \\
\text { family business }\end{array}$ \\
\hline Kel & 25 & Spanish & & X & English & Spanish & N/A \\
\hline Jan & 40 & French & & X & English & French & Homemaker \\
\hline Adi & 35 & French & & X & French & $\begin{array}{l}\text { English and } \\
\text { German }\end{array}$ & Homemaker \\
\hline
\end{tabular}

Notes: $\mathrm{U}=$ Undergrad $\mathrm{P}=$ Post-baccalaureate 


\section{Procedures and Data Analysis}

The researcher collected the data at three different points during the semester while the participants took a methods course called Teaching a Second Language. Table 2 shows the data collection timeline.

Table 2

Data collection

\begin{tabular}{lll}
\hline Data collection point & Data collection tool & \begin{tabular}{l} 
Data collection focus \\
\hline First week of classes
\end{tabular} \\
& Reflective paper (Appendix A) & $\begin{array}{l}\text { Participants were asked to } \\
\text { consider past language-learn- } \\
\text { ing experiences to gain a per- } \\
\text { spective on their beliefs about } \\
\text { language learning prior to } \\
\text { starting the methods course. }\end{array}$ \\
\hline Ninth week of classes & $\begin{array}{l}\text { Philosophy of teaching paper } \\
\text { (Appendix B) }\end{array}$ & $\begin{array}{l}\text { Participants were asked to } \\
\text { reflect on their beliefs about } \\
\text { effective language-teaching } \\
\text { practices. }\end{array}$ \\
\hline Thirteenth week of classes & $\begin{array}{l}\text { Authentic assessment-mock } \\
\text { job interview (Appendix C) }\end{array}$ & $\begin{array}{l}\text { Participants were asked to } \\
\text { discuss their beliefs about lan- } \\
\text { guage learning environments, } \\
\text { students' learning styles, } \\
\text { teachers' classroom manage- } \\
\text { ment skills, and teachers' ad- } \\
\text { vocacy efforts. }\end{array}$ \\
\hline
\end{tabular}

The first collection point took place during the first week of classes, and the instrument was a three-page reflective essay about their experiences as language students in high school. The participants wrote about their teachers' pedagogical choices in relation to class activities, class content, what made teachers "good," and the characteristics associated with poor teachers. The second data-collection point took place during the ninth week of classes. The instrument was a three-page teaching-philosophy essay. The participants wrote about their beliefs regarding effective practices in foreign language instruction in the areas of classroom environments, teachers' methods, learners' learning experiences, and the role of assessment in the language classroom. The third data-collection point took place at the end of a 13-week course. The instrument used was a type of authentic assessment that helped students demonstrate what it means to be an effective language teacher in a real-life situation that would bring theory and practice together. This assessment combined three elements of Angelo and Cross's (1993) Classroom Assessment Techniques (CAT): an annotated portfolio, invented dialogues, and exam evaluations. This authentic assessment asked the students to prepare for a final oral exam in the form of a job interview. Students received an authentic job ad according to their educa- 
tion major (ESL, French, or Spanish). Afterwards, they had to prepare for this interview by putting together a teaching portfolio with material developed during the course by visiting the school's job-listings website and preparing a list of possible questions. They were asked five more questions that were not part of the list. The answers to these questions were used as data for this study. Each student received a time slot of 20 minutes to complete this interview. The interviews were videotaped, and the answers to the five undisclosed questions were transcribed.

Each answer during the job interview and the two essays was iteratively, inductively, and deductively coded according to themes that revealed conceptual knowledge and espoused beliefs in the areas of classroom management, planning, assessment, and students' and teachers' roles. Following Bernard and Ryan's (2010) transcription protocol during the inductive coding process, the raw data were read and reread in order to familiarize the researchers with the participants' answers and to facilitate the creation of the categories listed above. Those cognitive orientations were then deductively coded, since the researcher brought a conceptual lens a priori to the analysis of the data. A matrix of analyses was created according to Habermas's three types of cognitive interests - technical, practical, and emancipatory - in combination with the five pedagogical areas listed above. Next, the researcher and an aide compared each of the students' answers and classified them according to the definitions of the three cognitive interests and five pedagogical areas in this matrix. Finally, the researcher and second reader used this matrix to find out the frequency or different levels of saliency in which each of the cognitive levels stood out in the students' narrative.

\section{Results}

This research looked at the participants' most common cognitive interests and classified them into five areas of teaching performance: classroom management, planning, assessment, and students' and teachers' roles. This study also focused on finding the levels of cognitive interests in which nine pre-service world-language and ESL students operate prior to student teaching, and whether these interest levels change during the methods course called Teaching a Second Language. 


\section{Cognitive Interest Domains and Areas of Teaching Performance}

This study organized the data into five teaching performance indicators to find out what the participants' most common beliefs were in each area of teaching performance according to Habermas's levels of cognitive interests. The areas were classroom management, student role, teacher role, pedagogical method, and assessment.

Technical cognitive interest domain. The study participants believed that having an organized plan, clear rules, a reward system, and good time management were indicators of having good classroom management skills. During the job interview, Adi highlighted the need to provide structure to teenage students in order to enhance their learning experience:

Teenagers - they need some structure. So they need to know, that when they come to my class, there's a certain structure to the lesson. So uh, [in] each class there will be three parts: the introduction, the procedures part with the main activity or activities, and the closure part. (Adi)

The participants who held beliefs at the technical level described student and teacher roles in simplistic ways that painted a fixed idea of both roles. One of the most commonly held beliefs was that teachers were always in charge and that one important task was to motivate their students and attend to their needs. These participants used the pronouns $I, m y$, and they when describing language teachers' and students' roles in the classroom, which indicates a hardline division of roles:

For my middle school classes, I wish to instill the values that I find more important and valuable in life. (Sam)

The role of instruction is to break down the material in a fashion where they will comprehend it easily and be able to have it and use it in their lives. Also, this role is something that should be taken seriously; if the instructor is not willing to help the students and break down the material to help them understand, then there is no simple way for the students to comprehend and learn this language. (Gab)

The most commonly held beliefs in the area of methodology emphasized the memorization of vocabulary, the importance of teaching grammar, and following the main textbook: 
It is imperative that students receive extensive practice with the language basics. They will master letters, numbers, greetings, adjectives, simple verbs and conjugations, phrases and sentences. (Kel)

Beliefs about assessment at this technical level emphasized it as a way to monitor and control students' learning as well as their role in reviewing material. Those beliefs also expressed the role of accountability for the student:

I plan to teach my students "Standardized Testing" for reading and writing as a genre, just like I would teach poetry as a genre. When you think about it, there is a specific way you analyze and answer questions about standardized texts, just like there is a specific way to read and evaluate poetry. Summative assessments leave little room for error, but they help me as a teacher evaluate class understanding, and they help my students evaluate their own learning. (Sam)

Practical cognitive interest domain. The most commonly held beliefs about language classroom management, at the practical level, were the need to offer language immersion experiences and the use of teams or groups to help develop communicative language skills and the necessary student support. The role of the student and teacher was mainly that of negotiators of meaning. Students are perceived as unique, autonomous, and having a diverse set of needs. The teacher is passionate, open to new ideas, creative, and offers students support at all times. The main pedagogical method supports the exchange of meaning, uses authentic texts, and provides students with rich input. There is an emphasis on experiencing the language at a personal and intimate level:

I believe that students will remember what they learn better if they are able to make sense of the information themselves, often in working with teammates. (Adi)

So I would be very interested to see if there [were] certain things that we could look at in terms of the cultural unit that we could teach through the medium of French. So, when we're talking about French culture, rather than talk about it in English, let's talk about it in French. (Jan)

Assessment, at this cognitive level, would help the teachers modify and adjust their pedagogies and motivate students' growth in their language skills. Mistakes are considered necessary for learning:

I want my students to understand that we are all in this learning process together. Formative assessments will help me build up my understanding 
of how students are learning and assimilating the language. They will help me adapt my instruction to better suit the needs of my students and to maximize their learning potential. (Jan)

Emancipatory cognitive interest domain. The participants' beliefs at this level emphasized the importance of fostering an inclusive and welcoming classroom that respected differences, and providing a safe space free of fear tactics that would support students' growth and curiosity and respect their unique identities. The role of the teacher is to be passionate, positive, and fully committed to their students' success:

The student-centered approach allows for many teachable moments as students become highly engaged with the content. Once they make relevant connections to their own lives, the students then take ownership of their education. (Vic)

I will discover their cultures by allowing the students to feel comfortable enough to share their cultures in class, and then creating projects and assignments based on their cultures to create inclusivity and understanding of other cultures. ... All I wish to do with my students is to teach them to be ready for the world while learning to be better people in a comfortable, fun environment we create together. (Kim)

There were no clear beliefs in the areas of methods and assessment at this level.

\section{Operational Cognitive Domains}

The data showed that the nine pre-service teachers functioned mainly at the technical and practical domains during the semester (see Table 2). They also operated at different levels of cognitive interests with different levels of saliency, which supports what Borg (2003) stated about teachers developing in unique ways. One cognitive level was more salient than the other at different points in the semester. Those students who started the semester functioning at a technical domain started functioning at a technical and practical level at mid-semester and at the end of the semester. Those students who started functioning at a practical domain did not experience any change, and very few started to function at the emancipatory domain toward the end. 
Table 3

Students' Cognitiv Interest Domains

\begin{tabular}{|c|c|c|c|c|c|c|c|c|c|}
\hline \multirow{2}{*}{$\begin{array}{l}\text { Time } \\
\text { Name }\end{array}$} & \multicolumn{3}{|c|}{$\begin{array}{l}\text { Beginning of the } \\
\text { semester }\end{array}$} & \multicolumn{3}{|c|}{ Middle of the semester } & \multicolumn{3}{|c|}{ End of the semester } \\
\hline & $\mathrm{T}$ & $P$ & $E$ & $\mathrm{~T}$ & $P$ & $\mathrm{E}$ & $\mathrm{T}$ & $P$ & $E$ \\
\hline \multicolumn{10}{|l|}{ Adi } \\
\hline \multicolumn{10}{|l|}{ Ele } \\
\hline \multicolumn{10}{|l|}{ Gab } \\
\hline \multicolumn{10}{|l|}{ Kel } \\
\hline \multicolumn{10}{|l|}{ Kit } \\
\hline \multicolumn{10}{|l|}{ Vic } \\
\hline \multicolumn{10}{|l|}{$\overline{\mathrm{Jan}}$} \\
\hline \multicolumn{10}{|l|}{ Mer } \\
\hline Sam & & & & & & & & & \\
\hline
\end{tabular}

Notes: $\mathrm{T}=$ Technical; $\mathrm{P}=$ Practical; $\mathrm{E}=$ Emancipatory.

\begin{tabular}{|l|l|l|}
\hline Salient & Somewhat salient & Not salient \\
\hline
\end{tabular}

The saliency of cognitive interests. The study participants held cognitive beliefs that exemplified mostly the technical and practical levels. Most of those operating at the technical level emphasized the need for efficiency, effectiveness, and the teacher's control of the classroom. Sam, for instance, believed that the use of multicultural posters would make her classroom more diverse and student-friendly. She also considered grammar essential in developing the literacy process of her students:

To develop cultural sensitivity in my classroom, I will fill my classroom walls with multicultural posters. This will not only expose my students to these different cultures, but it will also allow my students who experience these cultures feel more comfortable with their surroundings. I will utilize grammar activities when [they correlate] with my lessons as well as when my students are having difficulty with it. It is important to provide my students with an academic level of literacy rather than simply a conversational level. (Sam) 
Those operating at a practical level highlighted the importance of providing immersion opportunities for their students so they could develop strong communicative skills in the target language:

A teacher should make it a priority to speak in the target language as much as possible in the classroom, not only during communicative activities but also during explanations, as students can learn from these exchanges too. In doing so, students can realize that the target language is more than the object of study, it is a vehicle for communication. (Adi)

Gab was the only participant who held some emancipatory beliefs at the beginning of the semester, and these beliefs became more salient later in the semester, during the final interview. Gab said, "The concept of teaching a foreign language is something that has to be done with compassion. This compassion will help the students be unafraid of not knowing the language and have the will to further their knowledge with the language."

The subjects also exhibited different levels of saliency in their beliefs. However, one level was constantly more salient than the other two. For instance, Ele stated that she wanted her students to accomplish growth in the technical aspects of the languages and also have the drive to continue learning English on their own. Even though Ele was interested in how students feel in the languagelearning process, which is an example of someone working at a practical level, she believed that the way students feel is her responsibility. She also focused on the importance of developing students' linguistic knowledge. Her statement is an example of someone working mostly at a technical level of cognitive interest:

The skills my students will master will include: to be brave and confident when speaking English or trying to learn, various ways to use their vocabulary to create sentences and then eventually form paragraphs, and to constantly learn and improve their English language proficiency. I want my students to have a drive to continue learning English on their own outside of the classroom. (Ele)

Jan's position about the use of authentic material in the classroom is an example of someone operating at a practical level of cognitive interest. She not only highlights the importance of developing multi-literate skills for the students by using different sources, but she also points out that relying only on textbook material is not desirable:

Students need to be exposed to the target language in a real setting through a variety of texts - not just the standard textbook but also newspaper and 
magazine articles, blogs, websites, radio, TV, films, and advertisements. We live in a multi-literate world and we need to ensure that our students are able to communicate effectively in the same way. (Jan)

Changes in the saliency of the students' cognitive belief system. The group experienced two common saliency changes from a technical interest level to a practical level, and more than half started exhibiting some type of saliency in emancipatory interests either by mid-semester or toward the end of the semester. For instance, besides holding beliefs at the technical and practical levels, Vic started to operate at an emancipatory level mid-semester and toward the end of the semester. Vic's teaching philosophy emphasized the importance of students becoming the owners of their own learning process and feeling empowered:

The student-centered approach allows for many teachable moments as students become highly engaged with the content. Once they make relevant connections to their own lives, the students then take ownership of their education. My classroom approach is definitely student-centered, with guidance when necessary. This approach fosters students' critical thinking skills through the use of daily informal assessment in order for them to become self-sufficient learners. (Vic)

Six participants experienced different saliency levels of cognitive interests in their belief system during the semester, and three of the participants' belief system remained constant. Gab, Ele, Kel, and Adi held strong technical beliefs about language teaching at the beginning of the semester. Their belief system started to function at the practical level mid-semester, and at the end of the semester, Gab and Kel showed some emancipatory beliefs during the final interview.

\section{Discussion}

The results of this study indicated that Habermas's framework of cognitive interests describes and aligns with fundamental tenets and principles of language teaching, which allows language - teacher educator programs to look at their students' progress with a broader lens, one that shows not only the development of the students' conceptual knowledge but also their development of espoused beliefs. As Borg (2011) stated, those espoused beliefs "structure the ways in which knowledge is organized for application and for dissemina- 
tion in the professions" (p. 371). A student teacher functioning in a technical domain considers skill-building activities such as fill-in-the-blank sheets, short read-aloud exercises, grammar lessons, and vocabulary lists essential, since these lessons can be predictable and easier to control. These activities also offer a systematic way of organizing content, which makes this content more manageable. When Ele explained how a typical day in her classroom would be during the interview, she emphasized the need for her students to learn new vocabulary words. She said, "They should be able to identify a new type of word at the end of the lesson." Gab described her day as having her students do the following:

Read and speak, and having the kids speak, and read is very important because all students learn in different types of ways. Some learn better by hearing, some by speaking and some by physically reading. So by those three main things they are able to grasp the concept better and definitely learn from it in a positive way. (Gab)

These students also believed that they are in charge of every aspect of the class and even their students' motivation for learning.

Student teachers with a salient practical cognitive interest would consider the goal of communication as the one that would guide their pedagogical decisions. These students would plan around the students' communicative interests. These teachers would exhibit interest in using teams and community-building exercises. Connecting with peers and others would be central in their planning for language learning. During the job interview, Jen was asked to describe what a typical activity would be when she started teaching. She said the following:

They look at the foods they would offer in France, and then they can work together, all in French. They can work out what items they want to, you know, have on their menu and what items they want to prepare. And then we can invite their families into the classroom, so, bring the community into the classroom to sample their foods-we can have people serving them, you know what I mean? It would be a really great experience of learning about France and its great food heritage, and also, um, showing [what] we can do, what we can communicate in the language, what we can prepare from the country, and showing it to the rest of the school community. (Jen)

Jen highlighted the importance of working together and sharing a cultural experience as a community. 
One noteworthy finding was that this group of student teachers did not exhibit a salient or well-defined emancipatory belief system at the beginning of the semester, and only two, Kit and Vic, exhibited salient emancipatory interests toward the end of the semester. Most of their espoused beliefs at this level were about creating an inclusive classroom culture, free of fear, and being respectful of students' differences. During the job interview, Kit highlighted the "power of we" when asked about what she liked about the school she wanted to work for. She said:

I checked the school's website, their curriculum, and I noticed that the school's main slogan was "the power of we," and I thought that was amazing because it brings everybody together, the community and the stakeholders. And it is a powerful word to use, and I would love to be part of a community that brings everyone together and makes an effort to show everyone in the community - teachers, students, parents, staff - that everybody is important and vital in the learning experience. (Kit)

Kit emphasized the message of inclusiveness, which showcases beliefs at the level of emancipatory domain. Having a belief system at the emancipatory level could allow student teachers to become advocates of their own field, because it helps them to identify important forces in the decision-making process at a time when resources in the language field are scarce and threatened with elimination. Emancipatory beliefs also allow student teachers to look at their own practices from a critical-theory framework, with the goal of becoming transformative agents of their own pedagogy. Hopefully, this type of transformation could lead to changes in old practices - for instance, moving from a grammar-based classroom to a more communicative approach. Freeman and Johnson (1998) affirmed that an effective teacher education program should approach educational settings not as unbiased and neutral spaces where "educational practices are implemented" (p. 14), but as "dynamic environments" where student teachers need to learn how to negotiate issues of power and access.

\section{Limitations and Future Research}

One of the most evident limitations of this study is the possibility that Habermas's classification would have limited the process of theme recognition to the three main levels of cognitive beliefs. A second limitation is the possibility of students' biases in the answers given during the job interview, because this interview was part of the final oral exam, and the students might have included narratives that are only part of what was discussed in class. The third limitation is the data collection time. More definite changes in their belief 
systems could have been observed if the study's timeframe had been longer and continued during student teaching.

Future studies could use Habermas's framework to explore language teacher development further during student teaching and the first year of teaching. These studies could explore the role of the cooperating teacher's belief system in the development of student teachers' belief systems. Other studies could use quantitative measures that would allow for more generalizable results. In addition, other studies could look into levels of saliency at different points in the language educator's career.

\section{Conclusion}

The development of the belief system of future language teachers is key in determining the process of decision-making during their teaching years in the school system. Habermas offers a framework that captures the complexity of this belief system and will allow teacher educators to plan experiences that will help teachers develop beliefs not only at the technical and practical levels but also at the emancipatory level. Educators who are critical thinkers of their practices and the educational system as a whole are needed to promote change. Schools need teachers who are willing to transform and consider new ways of teaching, so their institutions develop more efficient ways to learn languages. This study shows that Habermas's framework could help teacher educators to facilitate the development of a more holistic teacher, one who not only understands the whats and hows of the field but also the forces that shape their practices.

\section{References}

Angelo, T. A., \& Cross, K. P. (1993). Classroom assessment techniques: A handbook for college teachers (2nd ed.). San Francisco: Jossey-Bass.

Basturkmen, H. (2012). Review of research into the correspondence between language teachers' stated beliefs and practices. System, 40, 282-295. https://doi.org/10.1016/j.system.2012.05.001

Bernard, H., \& Ryan, G. (2010). Analyzing qualitative data: Systematic approaches. Thousand Oaks, CA: Sage Publications.

Borg, S. (2003). Teacher cognition in language teaching: A review of research on what language teachers think, know, believe, and do. Language Teaching, 36, 81-109. https://doi.org/10.1017/ S0261444803001903 
Borg, S. (2011). The impact of in-service teacher education on language teachers' beliefs. System, 39(3), 370-80. https://doi.org/10.1016/j.system.2011.07.009

Brookhart, S. M., \& Freeman, D. J. (1992). Characteristics of entering teacher candidates. Review of Educational Research, 62(1), 37-60.

Brown, J., \& McGannon, J. (1998). What do I know about language learning? The story of the beginning teacher. Retrieved from: http://www.cltr.uq.edu.au/alaa/proceed/bro-mcgan.html. Accessed 22 March 2020.

Burns, A., Edwards, E., \& Freeman, D. (2015). Theorizing and studying the language-teaching mind: Mapping research on language teacher cognition. The Modern Language Journal, 99(3), 585-601. https://doi.org/10.1111/modl.12245

Butler, S. L. (1997). Habermas' cognitive interests: Teacher and student interests and their relationship in an adult education setting (Unpublished doctoral dissertation). Auburn University, Alabama.

Crookes, G. (2010). Language teachers' philosophies of teaching: Bases for development and possible lines of investigation. Language and Linguistics Compass, 12, 11261136.

Cumming, A. (1989). Student teachers' conceptions of curriculum: Towards an understanding of language teacher development. TESL Canada Journal, 7(1), 33-51.

Debreli, E. (2016). Pre-service teachers' belief sources about learning and teaching: An exploration with the consideration of the educational programme Nature. Higher Education Studies, 6(1), 116-127. https://doi.org/10.5539/hes.v6nlp116

Edgar, A. (2006). Habermas: The key concepts. New York: Routledge Taylor and Francis Group.

Freeman, D., \& Johnson, K. (1996). Reconceptualizing the knowledge-base of language teacher education. TESOL Quarterly, 32(3), 397-417.

Freeman, D., \& Richards, J. C. (Eds.). (1996). Teacher learning in language teaching. Cambridge: Cambridge University Press.

Gabryś-Barker, D. (2012). Reflectivity in pre-service teacher education: A survey of theory and practice. Katowice: Wydawnictwo Uniwersytetu Śląskiego.

Geelan, D. (2001). The empty centre: Power/knowledge, relationships and the myth of student centered teaching in teacher education. Australian Journal of Teacher Education, 26(2), 1-11. https://doi.org/10.14221/ajte.2001v26n2.3

Golombek, P. R., \& Johnson, K. E. (2017). Re-conceptualizing teachers' narrative inquiry as professional development. Profile, 19, 15-28.

Habermas, J. (1971). Knowledge and human interests (J. Schapiro, Trans.). Boston: Beacon Press.

Hennissen, P., Beckers, H., \& Moerkerke, G. (2017). Linking practice to theory in teacher education: A growth in cognitive structures. Teaching and Teacher Education, 63, 314-325. https://doi.org/10.1016/j.tate.2017.01.008

Johnson, K. E., \& Golembek, P. R. (2002). Inquiry into experience: Teachers' personal and professional growth. In K. E. Johnson \& P. R. Golembek (Eds.), Teachers' narrative inquiry as professional development (pp. 1-14). Cambridge University Press, Cambridge.

Kondrat, M. E. (1995). Concept, act, and interest in professional practice: Implications of an empowerment perspective. Social Service Review, 69(3), 405-428.

Mann, S. (2005). The language teacher's development. Language Teaching, 38(3), 103-118.

Ring, C. (2014). Social work training or social work education? An approach to curriculum design. Social Work Education, 33(8), 1101-1108. https://doi.org/10.1080/02615479.2014.902435

Scott, B. (1997). Curricular change in higher education: What we say and what we do. Paper presented at the annual meeting of the Mid-South Educational Research Association, November 1997, Memphis, TN. 
Sinprajakpol, S. (2004). Teachers' beliefs about language learning and teaching: The relationship between beliefs and practices (Unpublished doctoral dissertation). State University of New York at Buffalo, New York.

Varghese, M., Morgan, B., Johnston, B., \& Johnson, K. A. (2005). Theorising language teacher identities: Three perspectives and beyond. Journal of Language, Identity and Education, 4, 21-44. https://doi.org/10.1207/s15327701jlie0401_2

Vibulpol, J. (2004). Beliefs about language learning and teaching approaches of pre-service EFL teachers in Thailand (Unpublished doctoral dissertation). Oklahoma State University, Stillwater.

Wright, T. (2010). Second language teacher education: Review of recent research on practice. Language Teaching, 43(3), 259-296. https://doi.org/10.1017/S0261444810000030

Appendix A

\section{Language Learning Autobiography}

This essay provides the reader with a snapshot of your experiences and an introduction to your views regarding the teaching of a foreign language. Carefully consider your experiences as a student in your foreign language classes and describe your reaction to these classes in elementary, middle, and/or high school. You need not list a chronology of every school year. Well-written essays will answer some but not all of the following questions:

- What were the purposes of the teacher?

- What content was taught?

- What do you remember?

- What did students do in class?

- What did the teacher do?

- What made teachers good and what characteristics did you associate with poor teachers? Please limit your essays to no more than two, maximum three pages of double-spaced typing with 1" margins and a 12-point font such as Times New Roman.

Appendix B

\section{Philosophy of Teaching}

Develop a reflective essay that explores your beliefs regarding the purposes, methods, and content of foreign language teaching. Consider this essay as a written interview that you are having with a panel of middle or high school foreign language teachers. Please consider the following topics as you explain your rationale and teaching practices. Address these issues, but organize your answer according to your beliefs regarding effective practices in foreign language instruction.

- What is your rationale for teaching language in the middle or high school? This includes the knowledge you believe is most important, the values you will teach, and the skills that students will master in your classes.

- What approach will you take in teaching language to your students?

- How do you believe that students best learn a foreign language? What is the role of instruction about grammar? 
- Reflect on ways you will develop cultural sensitivity in your students.

- What are your career goals? And what are your plans to achieve those goals?

- What are your beliefs about summative and formative assessment in a language class?

Appendix C

\section{Mock Job Interview}

You will demonstrate an understanding of the central concepts discussed in class, such as the teaching and learning process in world language and ESL education and the national standards. In the form of a mock job interview, you will describe the importance of language study while placing it within a cultural, social, educational, and professional context. These interviews will take place during the last week and the week of finals. You will be given in advance the job description for a fictitious $\mathrm{K}-12$ world language/ESL teaching position. You are expected to dress professionally, and interviewers will consist of your course instructor and one or more practicing teachers/administrators with whom you are not familiar. On the night of the final exam, you must bring your portfolio, nicely organized. Each interview will last approximately 15 minutes.

The study used the participants' answers to the following questions:

- What should be the goal of the ESL/World Language classroom?

- How would you assess your students?

- Describe a typical day in your classroom.

- How do you accommodate the various learning styles of students within a class?

- How would you help advocate for the profession?/ ESL: How could you help make the ESL classroom part of the school community?

Maria Villalobos-Buehner

\section{Habermas'sche Theorie in der Forschung zu kognitiven Interessen von Fremdsprachenlehrern}

\section{Zusammenfassung}

Die Ausbildung zum Fremdsprachenlehrer umfasst sowohl theoretische und praktische Kurse, als auch pädagogische Praktika in der Schule (engl. practicum). Es wird erwartet, dass künftige Lehrer bei der Lehrtätigkeit während Praktikumszeit ihr konzeptionelles und praktisches Wissen einsetzen. Allerdings bei der Beurteilung ihrer Bereitschaft zur Lehrerarbeit wird lediglich das konzeptionelle Wissen in Betracht gezogen, während ihr Vorstellungssystem bezüglich Fremdsprachenlernen und -lehren ganz unberücksichtigt bleibt. Das erwähnte Vorstellungssystem bietet nicht nur einen wichtigen Einblick darin, wie sie ihr unterrichtsbezogenes Wissen organisieren, sondern weist auch auf ihre Offenheit für neue pädagogische Methoden hin. Im vorliegenden Artikel wird eine auf Grundlage der Theorie von Jürgen Habermas zu kognitiven Interessen konzipierte Untersuchung dargestellt, die sich auf die Analyse der Vorstellungen von neun künftigen Fremdsprachenlehrern zum Abschluss ihres methodischen Kurses bezieht. Die Analyse basiert auf Reflexionsessays betreffend un- 
ter anderem kognitive Interessen der künftigen Lehrer sowie die Unterrichtsmethoden und Leistungsbeurteilung im Fremdsprachenlehren. Aus der Analyse ergibt sich, dass man bei der Bildung künftiger Lehrer die vorstellungsfördernden und auf den Verselbstständigungsprozess bezogenen Erfahrungen berücksichtigen sollte. Dies könnte die künftigen Lehrer bei den Bestrebungen unterstützen, ihre Autonomie im Bereich der Bewältigung von schweren Umweltbedingungen zu entwickeln oder die neuen pädagogischen Methoden umzusetzen.

Schlüsselwörter: künftige Lehrer, Vorstellungssystem, Jürgen Habermas, kognitive Interessen 